\title{
A FRAMEWORK OF PROCEDURAL CONSIDERATIONS FOR IMPLEMENTING VIRTUAL REALITY IN DESIGN REVIEWS
}

\author{
Silvia Mastrolembo Ventura ${ }^{1,2}$, Fadi Castronovo ${ }^{3}$, Dragana Nikolić ${ }^{4}$ and Angelo L.C. Ciribini ${ }^{2}$ \\ ${ }^{1}$ Politecnico di Milano, Milano, Italy \\ ${ }^{2}$ University of Brescia, Brescia, Italy \\ ${ }^{3}$ California State University East Bay, Hayward, United States of America \\ ${ }^{4}$ University of Reading, Reading, United Kingdom
}

\begin{abstract}
The implementation of immersive virtual reality in the construction sector is experiencing a period of renewed interest since the research efforts of the early 2000s. VR-related applications are increasing in number and scopes, with a focus on communication and analysis of design intents. On the other hand, procedural challenges still obstacle their effective adoption for such purposes. The paper proposes a preliminary set of procedural considerations to take into account when immersive VR is used for feedback collection in design reviews. It is the result of an inductive approach associated with qualitative research methods based on seven semi-structured interviews with representative design stakeholders (i.e., twenty-four), including clients, designers, endusers and an accessibility expert. They were asked to evaluate VR adoption for the usability-focused analysis of a new school building. The framework represents a first step to address in a systematic way the practical implications related to VR-aided design reviews, especially when clients and end-users are involved.
\end{abstract}

\section{Introduction}

Research and applications related to Virtual Reality (VR) in the Architecture, Engineering, Construction and Facility Management (AEC/FM) industry are steadily increasing in number and scopes. This growing interest in VR systems, which are currently considered as one of the next trends of digital innovation (Mansouri \& Akhavian, 2018), is closely linked to the ever-increasing adoption of Building Information Modelling (BIM) processes, procedures and technologies that characterises the on-going digital transition of the industry.

A building information model, in fact, could be the starting point for the development of a virtual facility prototype. In product design, virtual prototypes of design proposals are known as the anticipation of a product that does not exist in reality yet (Bordegoni \& Rizzi, 2011). Virtual facility prototypes can be also effectively explored, tested and evaluated before being physically realised (Tutt \& Harty, 2013). Often, the use of virtual prototypes implies the adoption of virtual reality systems as visualisation and interaction platform. In particular, immersive virtual environments allow stakeholders to experience the full-scale representation of a virtual facility prototype in an intuitive and engaging manner through immersion and sense of presence (Paes et al., 2017). Based on those characteristics, immersive VR could be classified as semi-immersive VR and fullyimmersive VR. The former is an experience where a portion of the field of view of the user is covered by the system; the latter is an experience where the entire field of view of the user is covered by the system thus increasing the sense of presence within the virtual prototype (Whyte \& Nikolić, 2018; Castronovo et al. 2013; Shiratuddin et al. 2004).

Previous studies discussed a range of purposes and use cases for VR implementation in the building process. Communication of design intents and design review have resulted to be the main purposes for implementing virtual reality in BIM-based design processes (Lather et al., 2018). Previous researches in product design as well as perspectives from both academia and industry in the construction domain show how virtual reality systems could support collaboration through improved communication and access to information for all the stakeholders, regardless of their technical background. It has been demonstrated, for example, how VR systems could support the demand-side of the building process, such as clients and end-users, who may lack technical expertise, to participate in the decision-making process more effectively than using only traditional representations (e.g., 2D drawings, renderings, videorenderings) to access information (Van den Berg et al., 2017; Paes et al., 2017; Castronovo et al., 2013; Bullinger et al.; 2010).

Immersive Virtual Reality in usability-focused design reviews

Within the multiple purposes and use cases VR systems could be applied for, the scope of this study has been narrowed down to the convergence that is currently on-going between BIM, VR and soft landings principles, which highlight the need for a smooth transition from design to operation through 
the early involvement of clients and end-users (BS 8536-1:2015). Virtual reality, in fact, has been also applied in previous researches as an occupancy evaluation tool to support clients, end-users and facility managers in the collaboratively evaluation of functionality and usability of building spaces in order to feed back into the design stage the experience of the built environment in operation (Whyte, 2002; Hilfert \& König, 2016; Tseng et al., 2017; Liu, 2017). For example, Liu et al. (2014) showed how virtual facility prototypes allow reviewers to deeper understand the implications of design decisions. Van den Berg et al. (2017) reviewed the literature to explore how design reviews can be supported by immersive virtual environments to communicate design intents as well as to ask for design feedback, allowing designers and clients to navigate through and comment on a design in progress. Exploration from a user perspective, participation in solutionfinding and feedback on a design proposal are the patterns they identified in relation to VR implementation in usability-focused design reviews.

\section{Research gap and scope of the paper}

Within this research background, virtual reality is being used "to feed back the knowledge that clients, and end-users have about inhabitation into the design stage" (Whyte, 2002). Virtual reality, in fact, could be used as part of a strategy of obtaining feedback adopting a participatory approach as an attempt to bridge the gap in understanding between designers and the demand-side (Van den Berg et al., 2017). On the other hand, while research in the application of virtual reality systems is growing, both technological and procedural challenges to its effective implementation still exist. The latter are within the scope of this study.

They are illustrated, for example, by the need to implement VR in a structured manner and as part of a larger narrative during design reviews (Whyte, 2002; Lather et al., 2018). Moreover, other practical implications should be considered such as the need to guide the navigation of the stakeholders through the virtual facility prototype, the need to consider contractual constraints preparing VR representations as well as the need for setting the most appropriate level of detail or realism that could greatly affect the quality of the feedback and the overall effectiveness of the design meeting (Whyte \& Nikolić, 2018; Liu et al. 2014; Whyte, 2002). Moreover, motion sickness, novelty effect and previous user experience with VR systems also affect the result of the design review (Ferdig, 2013; Khashe et al., 2018).

The need for addressing practical implications in a more systematic way as a guide for the design teams when planning to use VR with other stakeholders is within the scope of this study, which proposes a preliminary set of procedural considerations to adopt when clients and end-users are involved in VR-aided usability-focused design review meetings. This represents a first step into the development of solid and systematic procedural guidelines for implementing immersive VR in usability-focused design reviews effectively.

\section{Methodology}

\section{Data collection}

Practical experience is "the best guide" to "understand implementation of virtual reality" (Whyte, 2002). An inductive research approach based on qualitative methods for data collection and data analysis has been applied (Maftei et al., 2018; Liu et al., 2018; Van den Berg et al., 2017; Liu et al., 2014; Tutt and Harty, 2013). Seven semi-structured group interviews have been organised involving a representative panel of design stakeholders (i.e., twenty-four participants including clients, designers, end-users and an accessibility expert) in the evaluation of immersive VR as a medium to support the usability-focused analysis of a new school building (Table 1). The aim of the interviews was to investigate process-related aspects and practical implications for adopting virtual reality in design review meetings from the perspective of design stakeholders. Designers and clients were selected based on their previous experience with BIM implementation and involvement with design and procurement of school buildings. Moreover, an accessibility expert, who is both a designer and a wheelchair user, was involved to discuss usabilityrelated aspects, as well as a representative panel of end-users (i.e., school directors, students, teachers, parents) of a similar building.

Table 1: Organisation of the interviews

\begin{tabular}{clc} 
Session & Stakeholders involved & $\begin{array}{c}\text { Participants } \\
\text { (n.) }\end{array}$ \\
\hline 1. & BIM manager (architecture) & 1 \\
2. & Accessibility expert & 1 \\
3. & BIM manager (architecture) & 2 \\
4. & Public client & 3 \\
5. & BIM manager (architecture, & 3 \\
& structure, MEP) & 11 \\
$6 . \quad$ & End-users (school director, & \\
7. & teachers, students, parents) & 3 \\
\hline \multicolumn{2}{l}{ Total number of participants } & 24
\end{tabular}

Before starting the interviews, participants were first (1) briefed on the objective of the research and then (2) introduced to the VR environment, learning how to use it to move and interact within the virtual facility prototype. During the (3) navigation within the virtual facility prototype, stakeholders were asked to review operational requirements related to the functionality and effectiveness of internal spaces based on their use and destination (Table 2). Finally, semi-structured group interviews have been adopted 
as a method to further explore VR implementation from the perspective of each category of stakeholders.

A semi-immersive VR environment was used (Figure 1; Figure 2). It featured a stereoscopic projector and a single portable rear-projected wall with a usertracking system, while a 3D mouse, a flystick and a keyboard were used as VR controllers. The Virtalis Visionary Render visualisation package was used to import the Industry Foundation Classes (IFC) version of the building information model into the immersive virtual environment and to prepare the VR representation. Though the use of this specific type of VR system was determined by its availability, the focus was not on the system but on the user experience (Paes et al., 2017).

Table 2: Design requirements taken into account

Operational requirements of functionality and effectiveness for internal spaces of innovative schools

1. Functionality of building spaces in relation to their use and destination

2. Effectiveness of building spaces to ensure innovative learning methods

3. Accessibility and safety of circulation paths

4. Interchangeability of building spaces to adapt to current needs (e.g., classroom/laboratory)

5. Flexible aggregation of contiguous spaces

6. Upgrading of circulation paths for teaching or aggregative use

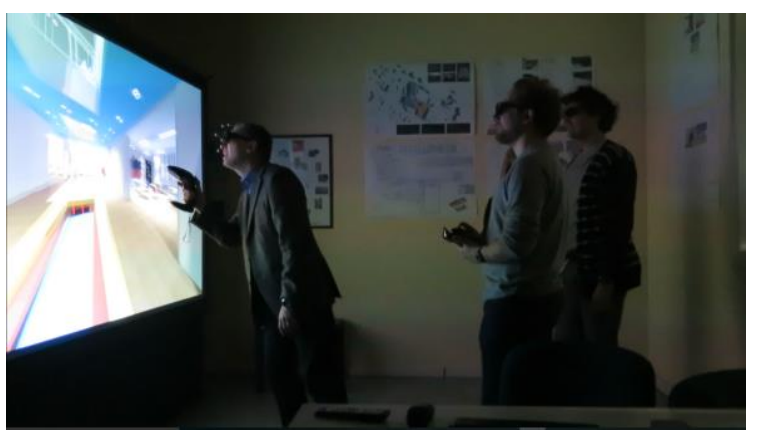

Figure 1: Interaction with the virtual facility prototype

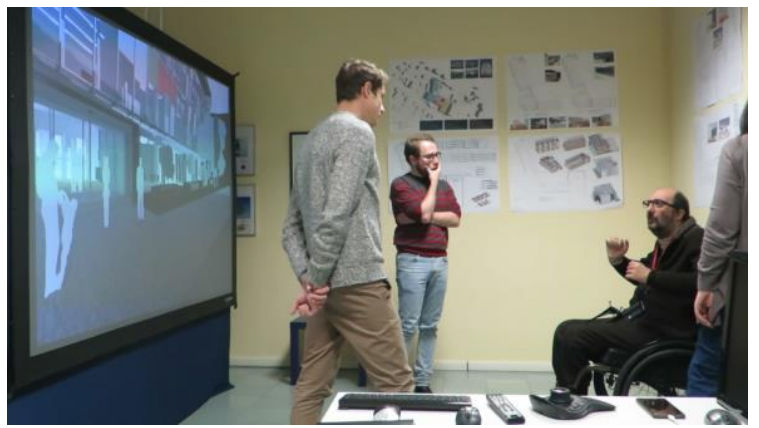

Figure 2: Review of the design proposal

The semi-structured interviews consisted of openended questions organised into four topics (Table 3 ). Team members had unique roles during data collection: one of the researchers, acting both as a facilitator during the design review and interviewer had a more personal interaction with the interviewees. Other three members of the research team were responsible for supporting the VR experience and, then, for audio recording the interview. Data were then collected and stored to be subsequently analysed.

Table 3: Preliminary coding schema based on the interview plan

\begin{tabular}{ll} 
Primary codes & Focus \\
\hline Contractual aspects & $\begin{array}{l}\text { to evaluate if the implementation } \\
\text { of VR systems might be } \\
\text { correlated to contractual } \\
\text { constraints } \\
\text { to understand how to manage the }\end{array}$ \\
$\begin{array}{l}\text { Level of } \\
\text { geometrical detail } \\
\text { VR representation at different } \\
\text { design phases and purposes of }\end{array}$ \\
$\begin{array}{l}\text { VR adoption } \\
\text { to consider the value of VR in }\end{array}$ \\
$\begin{array}{l}\text { with clients end- } \\
\text { users in VR }\end{array}$ & $\begin{array}{l}\text { suporting communication } \\
\text { sides of the design process } \\
\text { to evaluate if VR improves the } \\
\text { understanding of usability issues }\end{array}$ \\
$\begin{array}{l}\text { Stakeholder } \\
\text { engagement in }\end{array}$ & $\begin{array}{l}\text { in a design proposal compared to } \\
\text { traditional representations }\end{array}$ \\
usability-focused \\
\hline
\end{tabular}

\section{Data analysis}

An inductive grounded theory approach was applied to the analysis of qualitative data, which have been first coded, identifying key points of the data to be gathered, and then grouped into concepts and categories of concepts that have been finally used for generating the proposed contribution (Suwal \& Singh, 2018; Aksenova et al., 2018; Liu, 2017; Kumar, 2013).

Interviews have been taped and transcribed (Whyte, 2003). In order to code the interviews, the transcripts were imported in NVivo 12 software (Aksenova et al., 2018) as text files (i.e., *.docx format), organised in cases, which represent the units of observation of the analysis, and then classified by the profile of relevant stakeholders (i.e., designers, accessibility expert, clients, end-users) (Table 4).

\section{Table 4: Interview transcripts}

\begin{tabular}{lccc}
$\begin{array}{l}\text { Case } \\
\text { classification }\end{array}$ & $\begin{array}{c}\text { Files } \\
\text { (n.)* }\end{array}$ & $\begin{array}{c}\text { Participants } \\
\text { (n.) }\end{array}$ & $\begin{array}{c}\text { Interview } \\
\text { duration }\end{array}$ \\
\hline Designers & 3 & 6 & $1 \mathrm{~h} 40 \mathrm{~min}$ \\
Public clients & 2 & 6 & $1 \mathrm{~h}$ \\
$\begin{array}{l}\text { End-users } \\
\text { Accessibility }\end{array}$ & 1 & 11 & $40 \mathrm{~min}$ \\
expert & 1 & 1 & $30 \mathrm{~min}$ \\
\hline Total: & 7 & 24 & $3 \mathrm{~h} 50 \mathrm{~min}$
\end{tabular}

*One file corresponds to one group interview

During the interview analysis, sentences or group of sentences were assigned to primary codes. Primary codes, in their first version, reflected the interview 
plan and the related topics (Table 3). In a second round of coding, some sentences or groups of sentences have been re-assigned to new codes (Suwal \& Singh, 2018), which have been then grouped as secondary-level codes and, in some cases, as thirdlevel codes. Decision of code assignment was carried out by the authors based on "personal judgement and interpretation of what the sentences conveyed" (Suwal \& Singh, 2018). The assigned codes were rechecked iteratively in order to validate that the various sentences and groups of sentences were assigned to the right codes so to ensure that the assigned codes were accurately mapped to interpret the answers (Suwal \& Singh, 2018) (Table 5).

Table 5: Final coding schema

Primary codes and related sub-codes

\begin{tabular}{lcc} 
Primary codes and related sub-codes & Files & Ref. \\
\hline 1_Contractual aspects & & $\mathbf{3 9}$ \\
1.1_Public procurement routes & 7 & 27 \\
1.1.1_Transparency & 3 & 4 \\
1.2_Costs for VR implementation & 5 & 6 \\
1.3_EIR - Exchange Information & 2 & 4 \\
Requirements & & \\
1.4_Process management & 1 & 2 \\
\hline 2_Level of geometrical detail & & $\mathbf{1 0 6}$ \\
2.1_Materials & 4 & 10 \\
2.2_Lighting & 1 & 1 \\
2.3_Furniture & 7 & 26 \\
2.4_Stages of the building process & 3 & 5 \\
2.5_Type of stakeholder & 7 & 20 \\
2.5.1_Management of expectations & 7 & 15 \\
\hline 3_Communication with clients and end- & & $\mathbf{1 5 3}$ \\
users & & \\
3.1_Design visualisation using VR systems & 7 & 107 \\
3.1.2._Rendering & 4 & 14 \\
3.1.3_BIM Model & 4 & 40 \\
3.1.4_2D drawings & 7 & 25 \\
\hline 4_Stakeholder engagement in design & & $\mathbf{1 4 1}$ \\
review & & \\
4.1_Clients & 6 & 33 \\
4.2_End-users & 7 & 37 \\
4.2.1_Needs of end-users & 3 & 11 \\
4.3_Collaboration & 3 & 7 \\
4.3.1_Preparation of VR experience & 2 & 2 \\
\hline & & \\
\hline & &
\end{tabular}

The final coding schema reflects themes and patterns that emerged from data analysis and discovers issues of importance that were raised by participants (Kumar, 2013). Their role in VR implementation based on the interviews with the representative panel of design stakeholders is discussed in the next paragraph adopting a narrative approach.

\section{Research findings}

\section{Contractual aspects for VR implementation}

Clients and designers were those who discussed the contractual aspects of VR implementation the most, focusing on related procedural considerations (Table 6). According to them, the adoption of VR in the process should be managed as a BIM use (Kreider
2013) and aligned with project objectives and information requirements as defined by the client in the Exchange Information Requirements (EIR) (Quote_S1, S3, S5). Moreover, in their opinion, VR implementation should be considered as a rewarding factor during the tender evaluation in public procurements (Quote_S1, S3, S5). One of the designers stated to be ready to submit VR-compatible versions of a BIM model, considering it as:

"A further tool the client has to evaluate the design proposal in a more transparent way and to support the selection of the most valuable design proposal." (Quote_S1)

The majority of the designers, however, declared to be available to propose the use of VR in their precontract BIM Execution Plan (BEP) and to invest in the adoption of the necessary technology only once their tender offer is selected, emphasising a more project-level approach rather than an organisational one to the implementation of virtual reality (Quote_S3, S5).

According to the clients, VR implementation is not a priority of their digitalisation process (Quote_S7); however, they have recognised VR as an effective support for the analysis and communication of design intents (Quote_S4, S7). According to them, in fact, the use of VR potentially supports (1) collaborative practices as participatory design, (2) the multidisciplinary design coordination and (3) the review of a design intent, going behind normative texts and rather taking into account how the building will be effectively used by the occupants (Quote_S4, S7). On the other hand, they highlighted how:

"VR does not change the nature of public contracts. What has to be investigated is rather when to implement VR to involve end-users in order to effectively manage the design changes, for example the ones related to the functionality of the internal spaces, that this tool will inevitably stimulate the need for". (Quote_S7)

Table 6: Contractual-related consideration for
VR adoption*

\section{Level of detail considerations}

The level of geometrical detail and the level of information embedded within a BIM object represents the degree of reliability to which a BIM 
use is implemented (Kreider, 2013). The participants were asked to express their opinion about the necessary geometrical detail to evaluate the functionality of the internal spaces of the design proposal and to suggest what procedural considerations should be taken into account in relation to that specific aspect of VR implementation (Table 7). In particular, the presence of furniture, the use of textures and the lighting settings have been the aspects the participants considered the most (Figure 3 , Figure 4).

According to the designers, the level of geometrical detail for the representation of a design proposal within the virtual environment depends on (1) the purpose of the VR implementation, (2) the design phase when VR is implemented and (3) the stakeholders involved in the design review session (e.g., their level of technical expertise) (Quote_S1, S3, S5).

In relation to the purpose of VR implementation, the level of detail should be enough to allow stakeholders to evaluate the functionality of internal spaces. According to the accessibility expert, for example:

"If the accessibility of the internal spaces is considered and it is within the scope of the analysis, it means that elements that are strongly related to how a wheelchair user interacts with the space, such as, for example, the height of edges and handles of doors, as well as the height of sockets should be included in the virtual facility prototype". (Quote_S2)

Moreover, the interaction with pieces of furniture is needed to evaluate the flexibility and accessibility of internal spaces and they have to be included within the virtual facility prototype even if they are just placeholders to simulate how the end-user interacts with them within the designed space. In fact:

"The problem of accessible spaces is that, when furnished, they can become inaccessible. With virtual reality, I perceive the space and its relationship with furnishing going behind normative requirements: it is necessary". (Quote_S2)

On the other hand, other interviewees highlighted how the level of detail should also be considered from a contractual point of view because of the possibility that end-users may expect to see in the final building what they have experienced in the simulation (S3, S5). The presence of furniture is considered as an example: the building information model explored in VR contains pieces of furniture, which strongly characterise the design of the internal spaces. They are an essential part of the design of innovative schools and are needed to effectively evaluate the functionality and flexibility of learning environments. For example, one of the public clients said:
Table 7: Level of detail of the VR representation Consideration Description

\begin{tabular}{|c|c|}
\hline $\begin{array}{l}\text { Level of detail } \\
\text { of the virtual } \\
\text { prototype }\end{array}$ & $\begin{array}{l}\text { Set the level of detail of the VR } \\
\text { representation considering (1) the } \\
\text { purpose why VR is used; (2) the } \\
\text { design phase; ( } 3 \text { ) the stakeholders } \\
\text { engaged in the meeting and their } \\
\text { needs (avoid realism if not } \\
\text { necessary) }\end{array}$ \\
\hline
\end{tabular}

Level of Align the level of information need information of the virtual prototype with what is need of the required for the specific stage of the virtual design process for taking decisions prototype VR preparation

Schedule a preliminary VR preparation phase, investing time in delivering an appropriate virtual prototype based on what previously specified

Management Declare the level of detail during the of expectations meeting through visual cues to discern the decisions already made and those to be made about the design aspects (neutral for nondecided)

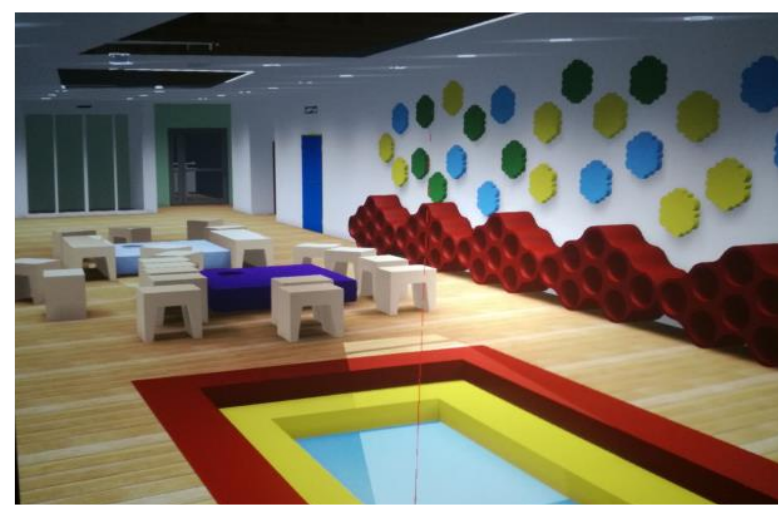

Figure 3: The corridor of the primary school with furniture and flexible walls becomes an educational space

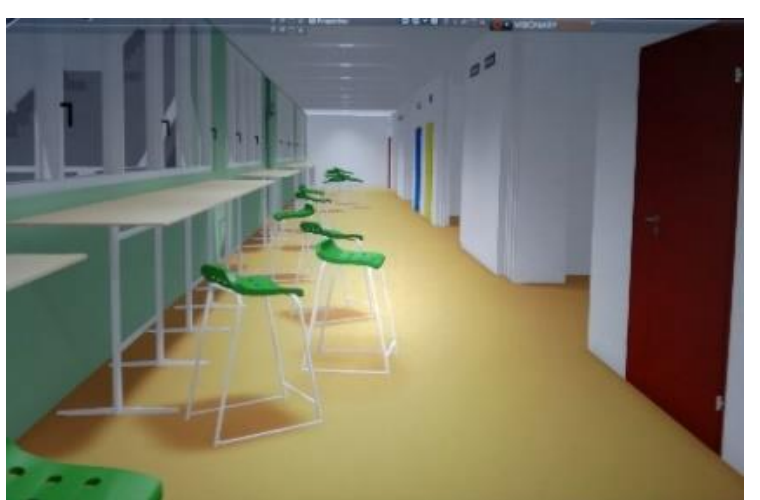

Figure 4: The corridor of the secondary school furnished for individual study

"The furniture defines the multifunctional spaces where teaching is done in an innovative way. I perceive the ennobling of the corridor as learning 
space much better than on 2D drawings. To date (to represent the same design aspect) they use renderings and text descriptions, while with immersive VR the communication of the design intent would be more effective." (Quote_S7)

On the other hand, according to the different types of public procurements, it may be possible that the furniture is not actually included within the design phase but demanded at a later stage of the building process and to the responsibility of other stakeholders (Quote_S4, S7). For that reason, the understanding of what should be included in the VR representation based on the stakeholders involved and the objectives of the design review session is essential and should be well discussed during the preparation of the meeting and the related development of the VR scenario (Quote_S7).

Regarding the target audience for using VR, managing the expectations of end-users in design review meetings has been the most discussed topic. For example, according to clients and designers, members of the design team understand that example furniture might be just a placeholder. On the other hand, end-users need more information in relation to how the building will be actually used in order to better understand the design and provide their feedback. When preparing a VR representation, the risk exists for too much realism, such as in textures and furniture that could create an expectation in endusers and clients. One of the architects involved in the VR sessions said:

"Users expect what they see, while designers know it may be just a placeholder. Not using textures would make the representation less misleading and avoid creating an expectation. The risk is that a strong characterisation of the space will become deceptive. The risk of creating false expectations already exists in renderings and in traditional representations." (Quote_S3)

Public clients agree with the need to calibrate the level of detail based on the stakeholders involved in the VR-aided design reviews. One of them said:

"The detail becomes an obstacle and not a help in participatory planning and stakeholder engagement because it confuses and creates expectations. What really counts is the functional, distributive and organisational aspect of the spaces”. (Quote_S7)

Moreover, the need to declare the level of detail of the VR representation at the beginning of the VRaided design review session emerged. One of the clients said:

"It is necessary to declare at the beginning (of the immersive session) what is decided and what is only a suggestion and a symbol. As a school director, I would have difficulty understanding what is contractual and what is not in this representation and to provide my feedback. For that reason, I would not show this representation to an end-user unless the elements in that are decided. In design phases in which decisions have not yet been taken, it is preferable to use neutral textures". (Quote_S7)

The end-users involved in the research confirmed those statements, further highlighting the need to consider the use of characterising elements such as furniture and textures within the virtual environment in order to avoid disappointment.

The level of detail of the virtual facility prototype should also be compliant with what is required for each design phase in the public procurement code (Quote_S4, S7). In relation to the design phases, one of the designers suggested that:

"During the concept design the graphical representation of the building information model within the virtual environment should include volumes and masses in order to allow stakeholders to evaluate overall dimensions of functional units and the interface between the building and the external context. During the detail design phase, instead, the level of detail should increase in order to allow users to evaluate internal spaces and circulation paths during the immersive sessions". (Quote_S1)

\section{Communication with clients and end-users}

Participants were asked what they believe to be the communicative potential of the VR system they tested before the interview (Figure 1) and how this could support, in their opinion, the effective communication of design intent to clients and endusers (Table 8). All the stakeholders expressed a positive opinion, highlighting the differences with traditional 2D drawings and renders; which were also available in the room to support design understanding. For example, one of the designers commented that the communication of the design proposal in a design review meeting typically starts with the floor plans followed by non-interactive rendering and video-rendering (S1). In this process:

"VR systems are useful for an immediate perception of the spaces that only technical experts can otherwise understand based on traditional representations." (Quote_S3)

At the same time the type of representation used will depend on the skill and background of the participant:

"As a designer I need to start from 2D drawings; it may be different for clients and for digital natives as the students. It would be interesting to evaluate it". (Quote_S3)

On the other hand, the school director as one of the end-users argues: 
"This [VR] type of representation allows us to better understand the design proposal and formulate an idea of the spaces stronger than looking at 2D drawings. We actually do not know how to read 2D drawings." (Quote_S6)

Thus, even if using virtual reality, multiple modes of representation would be needed to support the communication of the design proposal, including more conventional representations (Quote_S1, S3, S4). This has been also previously confirmed through the need for multimodal and interactive spaces, rather than VR alone (Lather et al., 2018, Balakrishnan et al., 2006; Whyte, 2002).

Table 8: Procedural considerations to support the communication of design intents using immersive VR

\begin{tabular}{ll} 
Consideration & Description \\
\hline $\begin{array}{l}\text { VR as a } \\
\text { medium in an } \\
\text { interactive } \\
\text { workspace }\end{array}$ & $\begin{array}{l}\text { Provide stakeholders with multiple } \\
\text { media to access design information } \\
\text { based on their needs and technical } \\
\text { expertise. An interactive workspace } \\
\text { should be set }\end{array}$ \\
$\begin{array}{l}\text { Risk for } \\
\text { novelty effect } \\
\text { and motion } \\
\text { sickness }\end{array}$ & $\begin{array}{l}\text { unfocused session, considering that a } \\
\text { novelty effect could influence } \\
\text { stakeholders as well as motion } \\
\text { sickness could reduce their } \\
\text { performance because of discomfort } \\
\text { and nausea }\end{array}$ \\
\hline
\end{tabular}

\section{Stakeholder engagement in design review}

Whereas communication here means "to present information about a facility in a method in which it can be shared or exchanged" (Kreider, 2013); to engage users, means to allow them to "express their views in an environment that is conducive to obtaining an honest and accurate understanding of their needs" (BS 8536-1:2015).

Interviewees also discussed how virtual environments could be used to engage stakeholders in design review meetings, effectively involving clients and end-users (Table 9). All the participants expressed a positive opinion, highlighting the differences between a VR-aided design review meeting and traditional processes. According to the accessibility expert, for example:

"Immersive reality has the potential to become an important tool for soft landings, as a communication bridge between the design and the occupancy of the building." (Quote_S2)

Moreover, in another meeting, three designers with different backgrounds all agreed in saying that:

"The immersive virtual environment should be used in order to engage end-users in the design process so that they can express an opinion and provide feedback”. (Quote_S5)

The participants discussed the potential benefits VR systems could provide to collaboration, as well as to the demand-side (i.e., clients, end-users) of the building process. At the same time, they also stated how planning stakeholder engagement in the process management is an important task. For example, one of the public clients said:

"When using immersive virtual environments in a participatory design process, I could acquire from my interlocutor information, design requirements and needs that I had not planned and considered and, in the process, I can adjust the design proposal." (Quote_S4)

Moreover:

"If the end-user is not the client, it is more difficult to involve him/her; however, clients and end-users are the stakeholders to be engaged because they will live and operate in the designed space and the communication of the design proposal has a greater impact for them" (Quote_S3)

However, if according end-users, navigating the model in VR may help them find answers more easily (S6), both designers and clients, as well as the accessibility expert, said that this process of communication of the design intent should be guided, confirming one of the consideration that already emerged discussing the contractual aspects of VR implementation. One of the clients, for example, highlighted how:

"Visualisation in virtual reality must be prepared according to the audience; for the same project and for the same project phase, different sessions and different views are expected". (Quote_S7)

Moreover, an agenda for the meeting should be organised in order to obtain the necessary feedback based on the objectives of the meeting. Liu et al. (2018) developed a process model describing the activities that characterise a usability-focused design review meeting. In relation to that, one of the interviewees said:

"Design review meetings involving end-users should be organised in three steps: (1) understanding of the design proposal from a functional point of view through 2D static views; (2) description of the intended use and operation of the building; (3) guided navigation within the immersive VR". (Quote_S1)

Both clients and designers agree in saying that leaving freedom of navigation to clients and endusers would entail the risk of a dispersive and unfocused session, which (a) does not consider the key aspects on which to make decisions and, not of minor importance, (b) would go beyond the maximum time for which it was proved that a session can be conducted without causing discomfort and 
nausea in the people involved due to virtual reality sickness. A third-person driver, expert in VR systems, should guide the stakeholders within the virtual facility prototype and they should not move by themselves without following pre-defined paths, viewpoints and activities that have to be preliminarily scheduled based on the objective of the meeting (Quote_S1, S2, S3, S5, S7).

\section{Table 9: Procedural considerations to support} stakeholder engagement using immersive VR Consideration Description

Pre-defined Prepare pre-defined paths and paths and viewpoints to guide the immersion viewpoint to based on the objectives of the navigate the meeting and the stakeholders model involved

Third-person VR Avoid training participants in driver to guide the immersion using VR systems and option for a third-person VR driver to guide the immersion based on the agenda set by the facilitator. This helps in managing time, meetings objectives, reducing risk for novelty effect and motion sickness

$\begin{array}{ll}\text { Design review } & \text { The facilitator (e.g., project } \\ \text { agenda } & \text { manager) should schedule phases } \\ \text { identifying } & \text { and decision gates of the design } \\ \text { decision gates } & \text { review meeting in order to guide } \\ & \text { VR preparation and stakeholder } \\ & \text { engagement }\end{array}$

\section{Discussion and conclusions}

\section{Discussion of findings and their contribution}

This study proposes a framework of procedural considerations (Figure 5) for implementing virtual reality systems in usability-focused design review meetings. The results confirm findings from previous studies (Whyte, 2002; Liu et al., 2014; Van den Berg., 2017; Hilfert \& König, 2016; Whyte \& Nikolic, 2018; Lather et al., 2018, Ferdig, 2013) and integrate them identifying the relevant categories of procedural considerations and practical implications that have to be taken into account when VR systems are used as media to access information in design reviews. The preliminary set that has been developed in this study represents a first step into the development of a systematic and comprehensive framework to guide designers in implementing VR systems. It may be refined and changed by future experience and research activities.

Results have revealed how some aspects related to the implementation of virtual reality in design reviews still need to be further investigated and, eventually, disseminated (e.g., contractual aspects). The perceived use of VR systems for reviewing design intents confirm that analysis and communication are the most adopted purposes for VR implementation in the AEC/FM industry (Lather et al., 2018). The topic of stakeholder engagement also emerged in close relation to the previous ones, highlighting the role of virtual reality as collaborative tool that can effectively converge with BIM procedures and soft landings strategies. Another topic that was widely discussed is the necessary level of geometrical detail to effectively visualise and navigate within a virtual prototype when designers, clients and end-users are involved in design reviews. In particular, the risk for providing expectations in clients and end-users was discussed. At the same time, the need for an intensive investment in time and cost for creating effective VR representations has been considered as one of the limits for the smooth adoption of VR technologies in the design review process, confirming also in this case aspects already emerged in previous research (Khesha et al., 2018).

\begin{tabular}{|c|c|}
\hline Literature review & $\begin{array}{l}\text { Semi-structured interviews with } \\
\text { a representative panel of design } \\
\text { stakeholders }\end{array}$ \\
\hline $\begin{array}{l}\text { Purpose of the design review } \\
\text { meeting (e.g., Liu et al., 2014) }\end{array}$ & $\begin{array}{l}\text { Prepare the VR representation } \\
\text { according to the objectives of the } \\
\text { design review }\end{array}$ \\
\hline \multirow{3}{*}{$\begin{array}{l}\text { Level of detail of the VR } \\
\text { representation (e.g., Whyte 2002; } \\
\text { Liu et al., 2014, Van den Berg et } \\
\text { al., 2017) }\end{array}$} & $\begin{array}{l}\text { Set the level of detail of the virtual } \\
\text { facility prototype }\end{array}$ \\
\hline & $\begin{array}{l}\text { Set the informative content of the } \\
\text { virtual facility prototype }\end{array}$ \\
\hline & $\begin{array}{l}\text { Management of expectations of } \\
\text { the stakeholders involved in } \\
\text { relation to the VR representation }\end{array}$ \\
\hline $\begin{array}{l}\text { Contractual constraints (e.g., } \\
\text { Whyte, 2002; Whyte and Nikolic, } \\
\text { 2018) }\end{array}$ & $\begin{array}{l}\text { Structure VR adoption as a BIM } \\
\text { use }\end{array}$ \\
\hline $\begin{array}{l}\text { Pre-defined navigation paths and } \\
\text { viewpoints to navigate the model } \\
\text { (e.g., Whyte, 2002, Liu et al., } \\
\text { 2014) }\end{array}$ & $\begin{array}{l}\text { Prepare pre-defined paths and } \\
\text { viewpoints to guide the navigation } \\
\text { through the model }\end{array}$ \\
\hline $\begin{array}{l}\text { Previous experience with VR } \\
\text { systems (e.g., Liu et al., 2014; } \\
\text { Paes et al., 2017; Khashe et al., } \\
\text { 2018) }\end{array}$ & $\begin{array}{l}\text { Avoid training people in using VR } \\
\text { systems. Prefer a VR driver and a } \\
\text { facilitator to guide the navigation }\end{array}$ \\
\hline $\begin{array}{l}\text { Collaboration (e.g., Whyte, 2002; } \\
\text { Bullinger et al., 2010; Van den } \\
\text { Berg et al., 2017, Liu et al., 2018) }\end{array}$ & $\begin{array}{l}\text { Organise the design review } \\
\text { agenda identifying decision gates } \\
\text { and steps for stakeholder } \\
\text { engagement }\end{array}$ \\
\hline \multirow{2}{*}{$\begin{array}{l}\text { Need for multiple media and use of } \\
\text { VR system in a wider narrative } \\
\text { (e.g., Whyte, 2002; Lather et al., } \\
\text { 2018) }\end{array}$} & $\begin{array}{l}\text { Organise an interactive workspace } \\
\text { including VR among multiple } \\
\text { media to access information }\end{array}$ \\
\hline & $\begin{array}{l}\text { Annotations should be linked to } \\
\text { the building information model } \\
\text { (e.g., BCF format) }\end{array}$ \\
\hline Novelty effect (e.g., Ferdig, 2013) & $\begin{array}{l}\text { Manage the risk for the novelty } \\
\text { effect }\end{array}$ \\
\hline $\begin{array}{l}\text { Motion sickness (e.g., Hilfert and } \\
\text { König, 2016) }\end{array}$ & $\begin{array}{l}\text { Manage the risk for motion } \\
\text { sickness }\end{array}$ \\
\hline
\end{tabular}

Concepts are mapped and colour-coded based on the relevant categories ([red]: stakeholder engagement; [blue]: communication; [green]: level of detail; [orange]: contractual considerations)

Figure 5: Preliminary framework of procedural considerations for VR implementation in usabilityfocused design reviews. 


\section{Limitation of the research}

As far as the research limitations concerned, they are related to both applications of findings and generalisations based on the methods used. This study dealt with an individual case (i.e., a school building design review with relevant stakeholders) and findings cannot be generalised if not compared with a wider set of building design reviews, specific design processes and particular type of design review meetings and related objectives. This research is thus limited to the generation of a preliminary framework of procedural considerations and practical implications for implementing VR in design reviews when clients and end-users are involved. On the one hand, findings provide evidence to results from previous researches; on the other hand, additional research is needed to test, refine and extend the theory that has been built here (Van den Berg et al., 2017). Moreover, the data set could be extended in additional research activities and findings need to be generalised in additional projects.

\section{Future works}

In order to validate the results of this study, the authors will evaluate the comprehensiveness of the framework of procedural considerations and, eventually, the need to extend and integrate it. For that reason, the authors have planned a next step of the research, which will be based on a series of talks with VR experts from both the academia and the industry. The talks will be managed in the form of semi-structured interviews and they will allow the authors to sharpen research generalisability and raise the theoretical level of the contribution providing further evidence on the need for a systematic and solid framework of procedural considerations to guide VR implementation from the practical experience of lead VR users. In future works the framework of procedural considerations could be matched to the phases of a VR-aided usabilityfocused design review session protocol in order to develop solid guidelines for VR implementation.

The growing interest of the construction sector towards virtual reality systems and interactive workspaces requires further research in order to effectively address technology investments and integration of those systems into design processes. In particular, a lack of understanding in relation to the added value, if any, generated by VR adoption exists. For that reason, comparative and quantitative research could be adopted to measure the added value of VR systems in design review (Khashe et al, 2018; Paes et al, 2017). Moreover, no guidelines are available to lead users to the selection of the most appropriate VR system based on their needs and expected user performance and interaction with the virtual facility prototype according to VR purposes and related uses. Furthermore, future research works should investigate how cognitive processes in collaborative activities, such as design review meetings when multiple stakeholders are involved, change because of the adoption of virtual reality systems. Finally, additional research should be related to the contractual aspects of VR adoption in design review meetings; the different types of design processes (e.g., user-centred design, participatory design) should be also taken into account.

\section{Acknowledgments}

ITC-CNR funded the PhD scholarship of one of the authors. TeamSystem Spa provided the VR system. The authors would like to acknowledge Barbara Angi and Lavinia C. Tagliabue for their contribution in the organisation of the interviews. Stefano Libretti, Carlo Cominelli and Marco Gelfi developed the design proposal and set the immersive virtual environment.

\section{References}

Aksenova, G., Kiviniemi, A., Kocaturk, T., \& Lejeune, A. (2018). From Finnish AEC knowledge ecosystem to business ecosystem: lessons learned from the national deployment of BIM. Construction Management and Economics, pp. 1-19.

Balakrishnan, B., Kalisperis, L. N., Muramoto, K., \& Otto, G. H. (2006). Multimodal virtual reality environment for architectural design (re) presentation. In: CAADRIA Computer Aided Architectural Design Research in Asia 2006.

Bordegoni, M., \& Rizzi, C. (2011). Innovation in product design: from CAD to virtual prototyping, Springer.

BS 8536-1:2015 Briefing for design and construction. Part 1: Code of practice for facilities management (Buildings infrastructure).

Bullinger, H. J., Bauer, W., Wenzel, G., and Blach, R. (2010). Towards User centred design (UCD) in architecture based on immersive virtual environments, Computers in Industry, 61(4), pp. 372-379.

Castronovo, F., Nikolić, D., Liu, Y. \& Messner, J. I. (2013). An evaluation of immersive virtual reality systems for design reviews. In: CONVR Construction Applications of Virtual Reality 2013

Ferdig, R. E. (Ed.). (2013). Design, Utilization, and Analysis of Simulations and Game-Based Educational Worlds. IGI Global.

Hilfert, T., König, M. (2016). Low-cost virtual reality 
environment for engineering and construction, Visualisation in Engineering, 4(2).

Khashe, S., Becerik-Gerber, B., Lucas, G., \& Gratch, J. (2018). Persuasive Effects of Immersion in Virtual Environments for Measuring ProEnvironmental Behaviors, In: ISARC Automation and Robotics in Construction 2018.

Kreider, R. G. (2013). An ontology of the uses of building information modeling. PhD Dissertation, Pennsylvania State University.

Kumar, S. (2013). Experience-based design review of healthcare facilities using interactive virtual prototypes. PhD Dissertation, Pennsylvania State University.

Lather, J., Leicht, R., \& Messner, J. (2018). Engaging with BIM: Interactive Workspaces in Facility Design and Construction. In: Construction Research Congress 2018.

Liu, Y. (2017). Evaluating Design Review meetings and the Use of Virtual Reality for PostOccupancy Analysis. PhD Dissertation, Pennsylvania State University

Liu, Y., Lather, J., \& Messner, J. (2014). Virtual Reality to Support the Integrated Design Process: A Retrofit Case Study. In: ICCCBE Computing in Civil and Building Engineering 2014.

Maftei, L., Nikolić, D., \& Whyte, J. (2018). Challenges Around Integrating Collaborative Immersive Technologies into a Large Infrastructure Engineering Project. In: $C I B$ W78 IT in Design, Construction, and Management 2018.

Mansouri, S., \& Akhavian, R. The Status Quo and Future Potentials of Data Analytics in AEC/FM. In: Construction Research Congress 2018.

Paes, D., Arantes, E., \& Irizarry, J. (2017). Immersive environment for improving the understanding of architectural 3D models: Comparing user spatial perception between immersive and traditional virtual reality systems. Automation in Construction, 84, pp. 292-303.

Shiratuddin, M. F., Thabet, W., \& Bowman, D. (2004). Evaluating the effectiveness of virtual environment displays for reviewing construction 3D models. In: CONVR Construction Applications of Virtual Reality 2004.

Suwal, S., \& Singh, V. (2018). Assessing students' sentiments towards the use of a Building Information Modelling (BIM) learning platform in a construction project management course. European Journal of Engineering Education, 43(4), pp. 492-506.

Tiainen, T., Ellman, A., \& Kaapu, T. (2014). Virtual prototypes reveal more development ideas: comparison between customers' evaluation of virtual and physical prototypes. Virtual and Physical Prototyping, 9(3), pp. 169-180.

Tseng, K. C., \& Huang, P. H. (2017). A systematic review of the potential application of virtual reality within a user pre-occupancy evaluation. In: UAHCI Universal Access in Human-Computer Interaction 2017.

Tutt D. and Harty C. (2013). Journeys through the CAVE: the use of 3D immersive environments for client engagement practices in hospital design. In: ARCOM Researchers in Construction Management 2013.

Van den Berg, M., Hartmann, T., \& de Graaf, R. (2017). Supporting design reviews with premeeting virtual reality environments. Journal of Information Technology in Construction (ITcon), 22(16), pp. 305-321.

Whyte, J. (2002). Virtual Reality and the built environment, Elsevier Science, Oxford.

Whyte, J. (2003). Industrial applications of virtual reality in architecture and construction. Journal of Information Technology in Construction (ITcon), 8(4), pp. 43-50.

Whyte, J. and Nikolić, D. (2018). Virtual reality and the built environment, $2^{\text {nd }}$ Edition, Routledge. 